\title{
CT Scans and Delays in Diagnosis of Stroke in Senegal's Regional Hospitals: A Multicenter Study of 655 Cases
}

\author{
Hamidou Deme1*, Nfally Badji1, Léra Géraud Akpo1, Oumou Dieng1, Abdoulaye Dione Diop², \\ Fallou Galass Niang2, Mouhamadou Hamine Toure'2, Ibrahima Faye1, Malick Diouf1, \\ Aicha Ndichout ${ }^{2}$, Marie Mbengue ${ }^{1}$, Cherif Mohamadou Aidara², Mamadou Ly², Ousmane Sano², \\ Ndiaga Matar Gaye ${ }^{3}$, Ousmane Cissé ${ }^{3}$, Abdoulaye Ndoye Diop², Aissata Ly Ba ${ }^{4}$, Sokhna Ba Diop ${ }^{2}$, \\ El Hadj Niang1
}

\begin{abstract}
${ }^{1}$ Radiology Department of the Aristide Le Dantec Hospital in Dakar, Dakar, Senegal
${ }^{2}$ Radiology Department of the CHNU de Fann in Dakar, Dakar, Senegal

${ }^{3}$ Neurology Department of the Fann University Hospital in Dakar, Dakar, Senegal

${ }^{4}$ Radiology Department of the Albert Royer Children's Hospital of Fann in Dakar, Dakar, Senegal

Email: *midouthio@gmail.com
\end{abstract}

How to cite this paper: Deme, H., Badji, N., Akpo, L.G., Dieng, O., Diop, A.D., Niang, F.G., Toure, M.H., Faye, I., Diouf, M., Ndichout, A., Mbengue, M., Aidara, C.M., Ly, M., Sano, O., Gaye, N.M., Cissé, O., Diop, A.N., Ba, A.L., Diop, S.B. and Niang, E.H. (2020) CT Scans and Delays in Diagnosis of Stroke in Senegal's Regional Hospitals: A Multicenter Study of 655 Cases. Open Journal of Medical Imaging, 10, 96-104. https://doi.org/10.4236/ojmi.2020.1020 $\underline{09}$

Received: March 26, 2020

Accepted: May 17, 2020

Published: May 20, 2020

Copyright (C) 2020 by author(s) and Scientific Research Publishing Inc. This work is licensed under the Creative Commons Attribution International License (CC BY 4.0).

http://creativecommons.org/licenses/by/ $4.0 /$

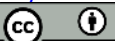

Open Access

\begin{abstract}
Stroke represents the $2^{\text {nd }}$ cause of mortality and $1^{\text {st }}$ cause of physical disability in the adult population. In Senegal, it represents 30\% of hospitalization and $2 / 3$ of the mortality in the department of neurology in the capital city, Dakar. Objective: To specify the types of stroke and to evaluate diagnostic delays in Senegal's regional hospitals. Materials and Methods: This was a retrospective, cross-sectional, descriptive, multicentric study for 4 years (from 2014 to 2017) including any patient presenting a clinical suspicion with a CT scan confirmation of stroke in one of the 9 regional hospitals in Senegal with a recruitment period of 6 months per hospital. CT scans were performed with a 16 slices machine in 6 hospitals, 4 slices in 2 hospitals and 2 slices in 1 hospital. We studied the types and location of strokes, the associated signs and the time from stroke onset to admission and the time from admission to CT scan. Results: 655 patients were retained including 322 men and 333 women for an M/F ratio of 0.96 . The average age was 63 years (range: 7 years, 112 years). High blood pressure was noted in $59.2 \%$ of patients and diabetes in $10.7 \%$ of patients. Strokes were ischemic in $76 \%$ of cases involving the middle cerebral artery in $73 \%$ of cases and hemorrhagic in $24 \%$, of which $80.7 \%$ were deep localized. A mass effect was noted in $7.5 \%$ of cases, an engagement in $6.9 \%$ of cases and ventricular hemorrhage in $2.7 \%$ of cases. The delay between the onset of the deficit and admission was less than 6 hours in $10.6 \%$ of patients. The time between the onset of stroke and admission to hospital was specified in 416 patients $(63.5 \%)$ of the study population, it was less than 6 hours in $10.6 \%$ of patients, between 6 hours and 24 hours for $29.3 \%$ and more than 24 hours for $60.1 \%$. Between admission and the CT scan, the
\end{abstract}


time was precise in 459 patients (70\%), it was less than 6 hours in $37.9 \%$, between 6 hours and 24 hours in $43.6 \%$ and more than 24 hours in $18.5 \%$. Conclusion: CT is central to the diagnosis of stroke in rural areas. However, there is a significant delay in diagnosis and management.

\section{Keywords}

Stroke, CT Scans, Diagnostic Delays

\section{Introduction}

Stroke is defined as the sudden onset of a neurological deficit due to a focal vascular cause. It is the second leading cause of death and the first cause of physical disability in adults [1]. In Senegal, it represents more than $30 \%$ of hospitalizations and 2/3 of mortality in the neurology department in Dakar [2].

No study has been carried out on the CT aspects of stroke in regional hospitals in Senegal, unlike the capital, or several studies have been carried out, the last of which focused on the possibility of thrombolysis of ischemic stroke in the hyperacute phase, by studying the time periods of consultation, management and ASPECTS score in 34 patients [3]. In addition, the absence of MRI available in the regions prompted us to carry out this work, the objectives of which were to specify the types of stroke and to assess diagnostic delays in regional hospitals in Senegal.

\section{Materials and Methods}

This was a retrospective, cross-sectional, descriptive, multicentric study carried out in 9 regional hospitals in Senegal (Figure 1), located between 70 to $607 \mathrm{~km}$ from the capital. Any patient seen in one of these regional hospitals with clinical suspicions and CT confirmation of stroke was included. Patients with a neurological deficit with a cause other than vascular were not included, nor were patients whose CT scan was performed outside of the regional hospital.

The CT scans were performed with Siemens 16-slice devices in 6 hospitals, GENERAL ELECTRICS Bright Speed 4-slice devices in two hospitals and Siemens 2-slice devices in one hospital.

The acquisitions were carried out without injection of contrast agent, and an additional acquisition with injection of iodinated contrast agent was carried out on 13 patients (2\%). We had performed axial, coronal and sagittal reconstructions. The reading was done in a parenchymal window.

The parameters studied on CT scan were the types of stroke, vascular territories of ischemic strokes, location of hemorrhagic strokes and associated signs. With respect to diagnostic delays, we assessed the time from stroke onset to hospital admission and the time from hospital admission to CT scan 
completion.

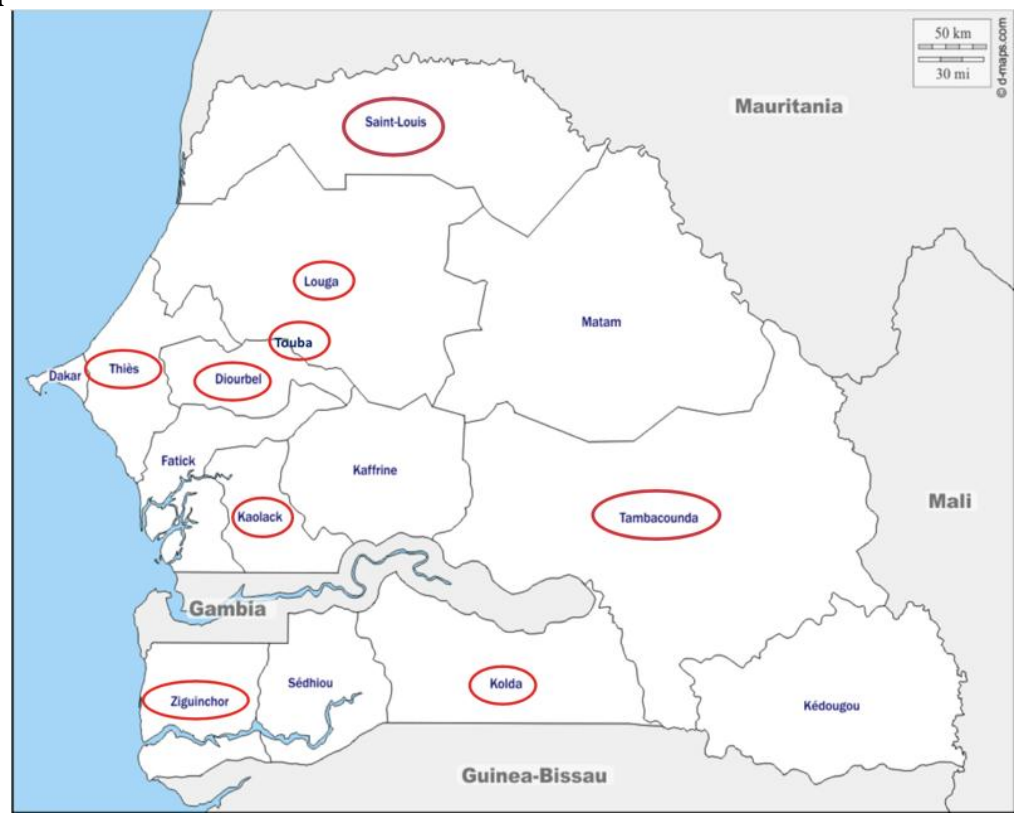

Figure 1. Map of Senegal showing the regions covered by the study (red boxes).

For the period between the onset of the deficit and admission to the hospital, the questioning of the patient's escorts made it possible to specify this in the file. For the time between admission to the hospital and the CT scan, the arrival time was systematically mentioned in the ER file.

Our data was captured and plotted on Excel 2007 and analyzed on SPSS 20.0. We performed the Student and $\mathrm{chi}^{2}$ tests with a p-value of less than 0.05 .

\section{Results}

Six hundred and fifty-five (655) patients were selected to perform this work, 322 men and 333 women for an M/F ratio of 0.96 . The mean age was 63 years with extremes of 7 years and 112 years and a standard deviation of 3.262. As antecedents, there was high blood pressure in $59.2 \%$ of patients, diabetes in $10.7 \%$ of patients and emboligenic heart disease in $3.7 \%$ of patients.

Strokes were ischemic in $76 \%$ of patients (Figure 2) and hemorrhagic in $24 \%$ of patients (Figure 3 ).

Ischemic stroke affected the middle cerebral artery in $73 \%$ of the cases, the anterior cerebral artery in $5.4 \%$ of the cases and the posterior cerebral artery in $5.2 \%$ of the cases.

The distribution of patients by vascular territories of ischemic stroke is shown in Figure 4.

Hemorrhagic strokes were deep topography in $80.7 \%$ of cases and superficial topography in $14 \%$ of cases. The distribution of hemorrhagic strokes according to the topography is given in Figure 5.

Thirteen (13) patients (2\%) had a contrast enhancement and a ruptured aneurysm was the cause of bleeding in 6 patients $(0.9 \%)$. 
Associated signs were noted in $40 \%$ of the patients with a mass effect type in $7.5 \%$ of the cases, of cerebral engagement in $6.9 \%$, of ventricular hemorrhage in $2.7 \%$. The distribution of the associated signs is given in Figure 6.

In terms of diagnostic delays, the time between stroke onset and hospital admission was specified for 416 patients $(63.5 \%)$ of the study population, it was less than 6 hours in $10.6 \%$. The distribution of patients by time from onset of symptoms to hospital admission is shown in Figure 7.

The time between hospital admission and CT scan was reported in 459 patients $(70 \%)$ of the population. This delay was less than 6 hours in $37.9 \%$. The distribution of patients according to the time between hospital admission and CT scan is shown in Figure 8.

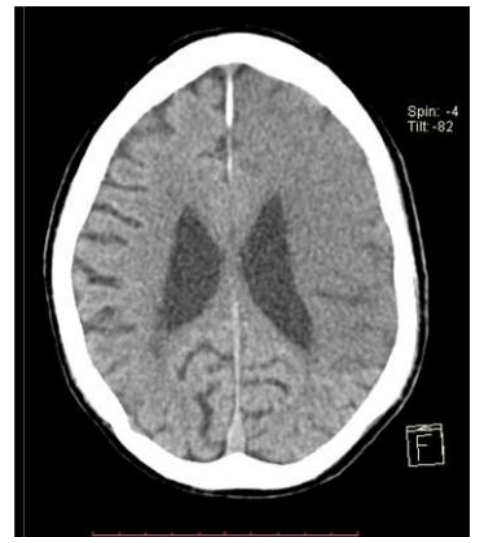

Figure 2. Axial section of cerebral CT scan without PDC injection showing a discrete range of left fronto-parietal hypodensity with cortical subcortical dedifferentiation and erasure of cortical sillions in a 60 -year-old woman, received for abrupt right hemiplegia of abrupt onset related to ischemic stroke in the territory of the left middle cerebral artery.

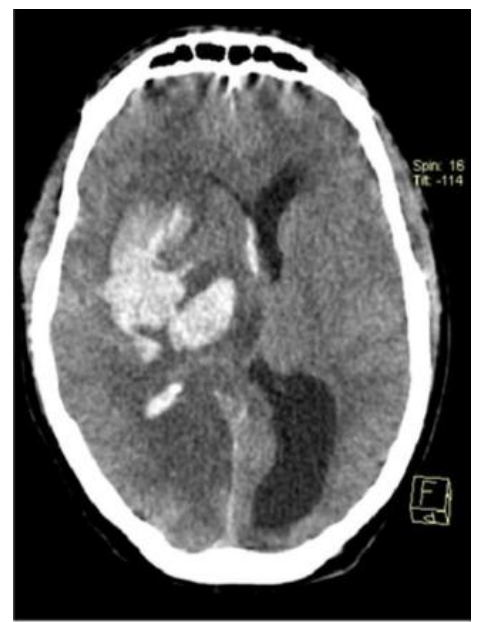

Figure 3. Axial section of cerebral CT scan without contrast injection showing deep spontaneous thalamic and right lenticular hyperdensity with significant perilesional edema associated with intraventricular blood suffusion and a large mass effect on the medial structures respon- 
sible for subfalcorial engagement with collapse of the homolateral ventricle in a 48- year-old patient treated for coma.

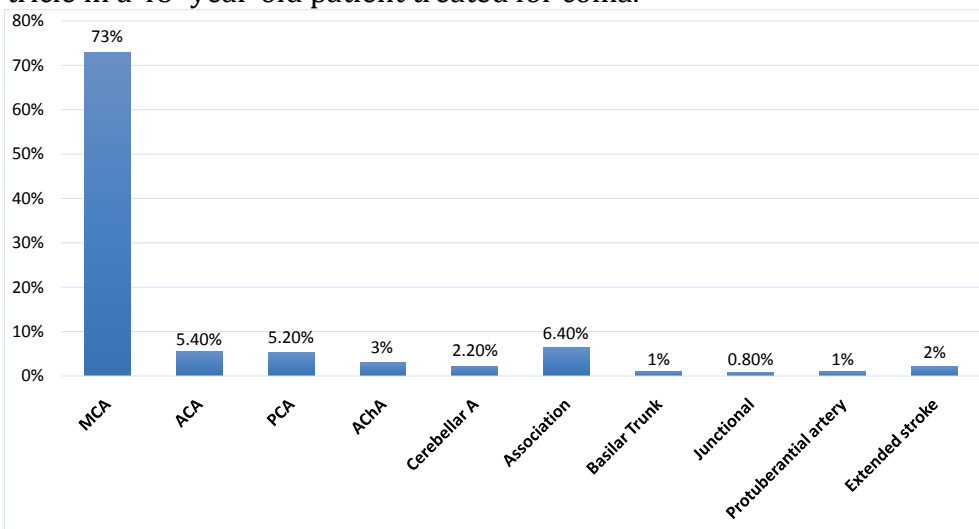

Figure 4. Distribution of ischemic strokes by vascular territories.

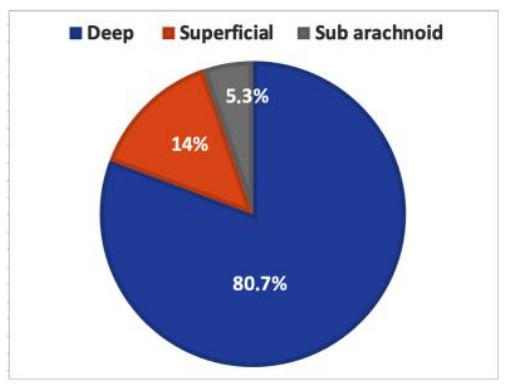

Figure 5. Distribution of hemorrhagic stroke according to topography.

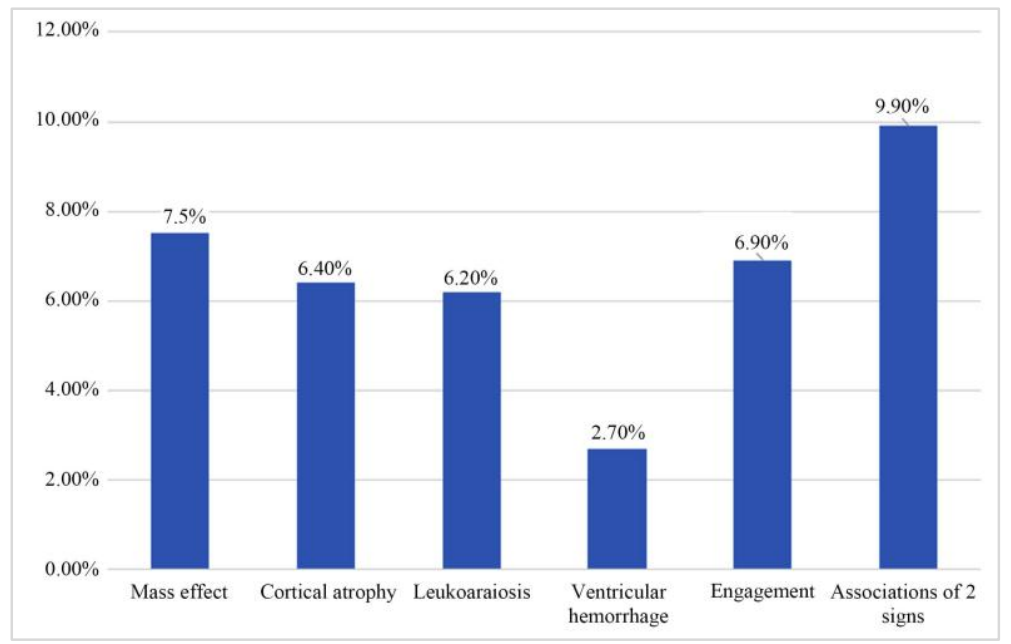

Figure 6. Distribution of associated signs.

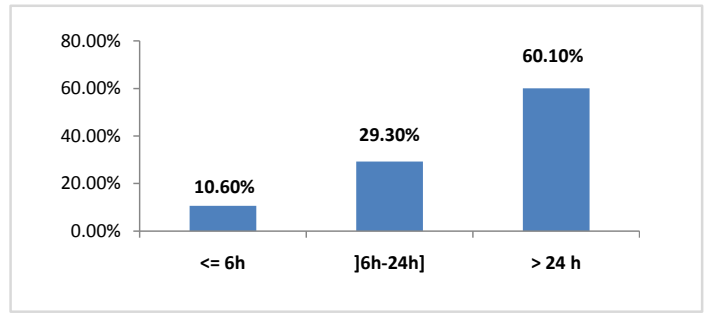


Figure 7. Distribution of patients by time from stroke onset to hospital admission.

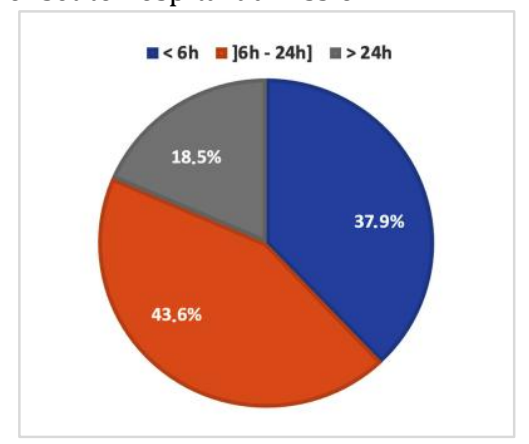

Figure 8. Distribution of patients according to the delay between admission to hospital and completion of the CT scan.

\section{Discussion}

Strokes were ischemic in $76 \%$ and hemorrhagic in $24 \%$, which is similar to the results of Diagne [4] who found in the capital Dakar 81\% ischemic strokes and $19 \%$ hemorrhagic strokes. According to Sagui [5], ischemic strokes account for two-thirds of strokes in sub-Saharan Africa (ranging from $63.3 \%$ to 84.7\%). In Occident, ischemic stroke accounts for $80 \%$ and hemorrhagic stroke for $20 \%$ according to Feigin [6]. The predominance of ischemic stroke is related to the multiplicity of cardiovascular risk factors [7]. In our study, $59.2 \%$ of patients were hypertensive, $10.7 \%$ had diabetes and $3.7 \%$ were carriers of embolic heart disease.

The middle cerebral artery represented $73 \%$ of the territory of ischemic strokes in our study. Ndoumba et al. [8] in Yaoundé found that $60.34 \%$ of the patients in the study suffered from a middle cerebral artery disease. This high frequency of involvement of the middle cerebral artery can be explained on one hand by a predilection for atheroma of the internal carotid artery leading to downstream lesions and on the other hand by the large caliber of this artery [9].

This vascular topography of ischemic strokes justifies the use of ASPECTS (Alberta Stroke Program Early CT Score) as a criterion of eligibility for possible thrombolysis [10]. Indeed, these criteria are applied to the middle cerebral artery. In rural areas where MRI is not yet available, the use of the ASPECTS score would make it possible to select patients who are candidates for thrombolysis for middle cerebral artery involvement.

Hemorrhagic strokes were deep localized in $80.7 \%$ of cases. Indeed, the central gray nuclei are the preferred site of bleeding related to high blood pressure. Their vascularisation is ensured by perforating arteries, which are very sensitive to hypertensive attacks [11].

Chronic high blood pressure accelerates the process of arteriosclerosis in the large arteries and arterioles of the brain. In small perforating arteries, such as lenticulo-striated or thalamic arteries, the hypertensive disease caus- 
es a slow degeneration of the media and the elastic membrane with the formation of micro aneurysms, which can rupture when pressure changes occur [12].

For superficial hematoma, an additional acquisition with contrast injection has been performed. In the case of a lobar hematoma or subarachnoid hemorrhage, contrast injection is mandatory to eliminate a vascular malformation [12]. In our study, 13 patients (2\%) had a second acquisition with contrast and a ruptured aneurysm was the cause of bleeding in 6 patients $(0.9 \%)$.

Mass effect was the main associated sign, noted in $7.5 \%$ of patients, resulting in compression and/or displacement of the medial structures, which in some cases could lead to engagement, which was the case in $6.9 \%$ of patients. Keita et al. in Mali, found a mass effect in $32.7 \%$ of cases [13]. Engagement is a life-threa- tening condition. As the cranium is inextensible, the existence of malignant edema or extensive hemorrhage can cause engagement in areas of weakness, the most common of which is subfactorial engagement [14].

In our series, the time between stroke onset and hospital admission was less than or equal to 6 hours in 10.6\% of patients; between 6 hours and 24 hours in $29.3 \%$ of patients and more than 24 hours in $60.1 \%$ of patients. This low percentage of patients admitted early could be explained by transport problems, a lack of awareness of the seriousness of this pathology. However, some patients first go to traditional healers where they lose precious time before being transported to appropriate care structures, which reduces their chances of functional recovery. Public awareness campaigns about the risk and symptoms of stroke would help reduce the incidence and severity of the disease and decrease the risk of handicap [15]. Indeed, a study conducted in France (Marseille) in 2007 demonstrated the need to raise public and professional awareness of the importance of early stroke care. The campaign, which consisted of putting up posters describing the clinical warning signs of a stroke at bus stops, subway stations and public places, doubled the number of strokes eligible for thrombolysis [16]. Information campaigns aimed at the general public should be encouraged and repeated because their effect is temporary. Information should not be limited to patients with vascular risk factors, but should be provided to the general population, including young people [17].

The time between admission to hospital and the completion of the CT scan was less than or equal to 6 hours in $37.9 \%$ of patients; between 6 hours and 24 hours in $43.6 \%$ of patients and more than 24 hours in $18.5 \%$ of patients.

This percentage remains very insufficient and could be explained mainly by financial problems, especially in elderly and destitute patients, but also by the very high number of admissions made in the emergency department. This delays the clinical examination of stroke patients and, indirectly, the CT scan, hence the need to establish a patient triage station in the emergency department. Education of stretcher staff and billing agents may reduce in-hospital 
delays.

In a study in the capital city Dakar, the average time to hospital was 6.25 hours and the median time 3.73 hours. Thirty-five percent (35\%) of the patients have consulted before 4 hours and 30 minutes, 24\% between 4 hours 30 minutes and 6 hours and 41\% beyond 6 hours. In the hospital, the average time between the patient's arrival and the CT scan was 41.76 minutes [3].

The hospital phase consists of immediate management of any patient suspected of having an acute stroke in order to shorten the "door to needle time" as much as possible. Time targets for this period are a maximum of 25 minutes to imaging, 60 minutes to thrombolysis and 120 minutes if thrombectomy is considered [18].

Currently, an average of 60 minutes is required until thrombolysis, leaving, at most, a delay of 120 minutes (210 minutes under the new protocols currently in progress) between the time of symptom onset and the patient's arrival in hospital. Despite the extension of the therapeutic window to 4.5 hours, it is important to remember that in the meantime, the earlier the thrombolysis, the more effective it is. All efforts must be made to shorten the time both intra- and extra-hospital delays. Early thrombolysis is currently the only treatment that can improve the prognosis of patients with ischemic stroke. It is significantly more effective when administered as soon as possible after the onset of symptoms [18].

The main limitations of the study without linked to the absence of data on the future of patients linked to a lack of computerization of patient data but also the retrospective nature of the study with the absence of precise data on diagnostic delays which could only be specified in $70 \%$ of the patients in the study.

\section{Conclusion}

Increased awareness of stroke symptoms among the general public and health care staff associated with an emergency department triage service and improved access to CT scans would significantly reduce diagnostic delays, which, combined with the ASPECTS criteria, would allow timely initiation of thrombolysis in rural areas. However, the implementation of a neurovascular unit remains essential in our country.

\section{Conflicts of Interest}

The authors declare no conflicts of interest regarding the publication of this paper.

\section{References}

[1] Vereshchagin, N.V., Sartorius, N., Orgogozo, J.M., Goldstein, M., Barnett, H.J.M. and Symon, L. (1989) Recommendations on Stroke Prevention, Diagnosis, and Therapy. Report of the WHO Task Force on Stroke and Other Cerebrovascular Disorders. Stroke: A Journal of Cerebral Circulation, 20, 1407-1431. 
https://doi.org/10.1161/01.STR.20.10.1407

[2] Diouf, F.S., Basse, A.M., Ndao, A.K., Ndiaye, M., Touré, K., Thiam, A. and Ndiaye, I.P. (2006) Pronostic fonctionnel des accidents vasculaires cérébraux dans les pays en voie de développement: Sénégal. Annales de réadaptation et de médecine physique, 49, 100-104. https://doi.org/10.1016/i.annrmp.2005.11.006

[3] Niang, F.G., Deme, H., Diop, A.D., Diouf, K.K., Niang, I., Thiam, M., Niang, E.H., et al. (2018) Evaluation pronostique des accidents vasculaires cérébraux ischémiques en phase hyper aiguë au CHU de Fann. Journal Africain d'Imagerie Médicale, 10, 194-198.

[4] Diagne, N.S., Camara, M., Cisse, O., Sy, A., Diop, A., Gaye, N.M., Diop, A.G., et al. (2016) Vécu post-AVC d'une cohorte sénégalaise: Quel facteur de risque pour quel items de qualité de vie. Journal de Réadaptation Médicale: Pratique et Formation en Médecine Physique et de Réadaptation, 36, 156-160. https://doi.org/10.1016/i.jrm.2016.07.001

[5] Sagui, E. (2007) Les accidents vasculaires cérébraux en Afrique subsaharienne. Médecine tropicale, 67, 596-600.

[6] Feigin, V.L., Lawes, C.M., Bennett, D.A. and Anderson, C.S. (2003) Stroke Epidemiology: A Review of Population-Based Studies of Incidence, Prevalence, and Case- Fatality in the Late 20th Century. The Lancet Neurology, 2, 43-53. https://doi.org/10.1016/S1474-4422(03)00266-7

[7] Pichard, F. (2014) AVC ischémiques au CHU de Saint-Pierre de la Réunion en 2013: Diagnostic des dysfonctionnements et réflexions sur l'optimisation de la prise en charge précoce. Médecine humaine et pathologie.

[8] Ndoumba, A.M., Ze Minkande, J., Chiabi, A., Nnomoko Bilounga, E. and Beyiha, G. (2012) Les accidents vasculaires cérébraux à l'Hôpital Gynéco-Obstétrique et Pédiatrique de Yaoundé. Schweizer Archiv fur Neurologie und Psychiatrie, 163, 54. https://doi.org/10.4414/sanp.2012.02348

[9] Mihindou, B. and Dyana, P. (2012) Aspects épidémio-cliniques des AVC dans le Service d'Accueil des Urgences du CHU Gabriel Touré.

[10] Demchuk, A.M. and Coutts, S.B. (2005) Alberta Stroke Program Early CT Score in Acute Stroke Triage. Neuroimaging Clinics, 15, 409-419. https://doi.org/10.1016/i.nic.2005.06.008

[11] Grossac, J., Fourcade, 0. and Geeraerts, T. (2010) AVC hémorragique aux urgences (hors hémorragie méningée). 52e congrès national d’anesthésie et de réanimation Médecins, Urgences vitals, Sfar, 1-12.

[12] Barth, A. (2000) Hémorragies intracérébrales non-traumatiques. 1ère partie: épidémiologie, physiopathologie et causes. Bulletin des médecins suisses, $\mathbf{8 1}$, 2601-2605. https://doi.org/10.4414/bms.2000.07757

[13] Keita, A.D., Toure, M., Diawara, A., Coulibaly, Y., Doumbia, S., Kane, M., Traoré, I., et al. (2005) Aspects épidémiologiques des accidents vasculaires cérébraux dans le service de tomodensitométrie a l'Hôpital du Point G. Médecine tropicale, 65, 453-457.

[14] Sermet, A. and Touzé, E. (2001) CEdème cérébral (OC) ischémique. Correspondances en neurologie vasculaire, 2, 34-37.

[15] Lahoud, N. (2015) Les accidents vasculaires cérébraux au Liban: prévalence, facteurs de risque et prise en charge dans les hôpitaux. Doctoral dissertation, Paris Est.

[16] Touré, K., Diagne, S.N., Seck, L.B., Sow, A., Ndiaye, M., Diop, M.S., Ndiaye, M.M., et al. (2010) Facteurs prédictifs de mortalité par accident vasculaire cérébral (AVC) a la Clinique Neurologique du chu de Fann, Dakar-Senegal. African Journal of Neurological Sciences, 29, 29-36. https://doi.org/10.4314/ajns.v29i2.70403

[17] Haute Autorité de Santé (2009) Accident vasculaire cérébral: Prise en charge précoce alerte, phase pré hospitalière, phase hospitalière initiale, indications de la thrombolyse. Recommandations pour la bonne pratique. Saint-Denis La plaine, HAS. 
[18] Freiburghaus, D., Kehtari, R., Yersin, B. and Michel, P. (2008) Accès a la thrombolyse lors d'AVC: Rôle des secours préhospitaliers et des médecins de premier recours. Revue médicale suisse, 4, 2444-2449. 